\title{
Taxes, tariffs, and the global corporation
}

\author{
James Levinsohn and Joel Slemrod* \\ University of Michigan, Ann Arbor, MI 48109, USA, and NBER, Cambridge, MA 02138, USA \\ Final version received June 1992
}

In this paper we develop some simple models of optimal tax and tariff policy in the presence of global corporations that operate in an imperfectly competitive environment. The models emphasize two important differences in the practical application of tax and tariff policy - tax, but not tariff, policy can apply to offshore output, and tariff, but not tax, policy can be industryspecific. Recognizing that multinationals' production decisions are endogenous to the tax and tariff policies they face, we investigate how a government should tax (or subsidize) domestically owned firms and how government should set trade policy.

\section{Introduction}

Tax policy and trade policy are alike because each affects the pattern of trade of goods and factors among nations. The conceptual similarity of tax and trade policy has been widely recognized and pursued in the context of models of perfect competition by, for examplc, Dixit (1985) and by Gordon and Levinsohn (1990).

The apparent empirical importance of imperfect competition poses new questions for optimal trade policy, many of which have been addressed by a series of papers on 'strategic' trade policy. These papers establish that there are situations in which government intervention such as trade subsidies may improve national welfare by increasing domestic firms' share of pre-tax profits.

The insights provided by the strategic trade policy literature have not been applied to tax policy questions. Yet the same arguments used to justify export subsidies are used in policy discussions to justify preferential tax treatment of U.S. multinationals. For example, it is widely asserted that the U.S. system of taxing the foreign-source income of its multinationals imposes a greater burden than is imposed on resident multinationals by the tax

Correspondence to: J. Slemrod, Department of Economics, University of Michigan, Ann Arbor, MI 48109-1220, USA.

*We are grateful to participants at the 1990 NBER summer institute and the 1991 International Seminar of Public Economics on International Taxation held at CORE for helpful comments. Thanks also to Avinash Dixit, Jim Hines, and referees for helpful suggestions. Much of this paper was completed while Levinsohn was at the Hoover Institution, and he thanks them for providing a wonderful research environment. 
systems of other developed countries, and therefore U.S. firms are placed at a 'competitive disadvantage'. See, for example, Arthur Young and Company (1988). For a general assessment of this argument, see Slemrod (1991). The idea is that a less burdensome system would help U.S. multinationals gain a greater market share and, implicitly, benefit the national interest.

In this paper we develop some simple models of optimal tax and tariff policy in the presence of global corporations that operate in an imperfectly competitive environment. The models emphasize important differences in the practical application of tax and tariff policy. Although international trade theory teaches us that trade taxes can be emulated by domestic tax instruments (a tariff, for example, is equivalent to a production subsidy and consumption tax at equal ad valorem rates), in reality this is not the case for two important reasons. First, domestic tax policy is typically set at the national level while trade policies are set at the industry level. While a tariff on imported sweaters may well be observed, a sales tax unique to sweaters is almost never observed. The ability to target fiscal policy to particular sectors is valuable because strategic policy is likely to be justifiable only for certain industries.

Second, in the era of the global corporation, the administration of trade and domestic tax policies imposes further non-equivalences. Trade policy operates at the border. As goods enter or leave the country, they are taxed or subsidized. Trade taxes, though, do not apply to goods produced abroad by domestically owned firms. For example, an export subsidy paid to domestic swcatcr manufacturers for each sweater exported does not generally apply to sweaters produced in Hong Kong and exported to a third country. Corporate taxes on resident corporations, though, are often applied on a worldwide basis. For example, the income earned by a multinational from sweater production either in the United States or in Hong Kong is subject to U.S. corporate taxes, although perhaps at different effective rates.

In this environment, how should a government tax (or subsidize) domestically owned firms and how should it set tariff policy? Targeting of incentives at the industry level can be accomplished using trade policies, but these will distort the firm's outward direct foreign investment which in turn alters the trade tax base. Alternatively, incentives that do not discriminate against outward direct foreign investment can be accomplished using national tax policy, but these taxes typically cannot discriminate between industries. Finally, any attempt to realistically model interactions between taxes, tariffs, and the global firm must allow for the possibility that the firm is an oligopolist. ${ }^{1}$ In this paper, we investigate international trade and tax policy when the location of an oligopolistic firm's production is endogenous to the policies set by a government.

\footnotetext{
${ }^{1}$ See, for example, the introduction of Ethier and Horn (1990).
} 
The paper proceeds as follows. We begin in section 2 by investigating tax and trade policy in a partial equilibrium model of an international duopoly. There we find that strategic policy should be implemented without regard to the location of production, thus preserving production efficiency. Tariff policy, which cannot apply to direct foreign investment and therefore cannot be uniform in its effect on home and foreign production, is dominated by tax policy.

In section 3 we investigate how the introduction of a non-strategic industry changes our results. We investigate optimal policy when only tax policy is available and when tax and trade policy may be used in tandem. We find that when industries differ in the appropriateness of strategic intervention, optimal tax policy, which alone cannot be industry-specific, should abandon productive efficiency in favor of the non-uniform policy which maximizes the strategic gain net of excess burden. Ideally, industryspecific tariff policy should be combined with general tax policy. We find that here too the production efficiency that characterizes domestic tax policy with perfect competition should in general be abandoned.

Section 4 concludes the paper. There, we summarize the policy implications of our models of tax and trade policy in the presence of imperfectly competitive multinational firms.

\section{The simplest story}

We begin with the simplest story - a partial equilibrium model of an international duopoly in which production in a common third country is possible. Even this simple story is an extension to the literature on international tax policy in the presence of direct foreign investment (dfi). Brander and Spencer (1987) and Levinsohn (1989) each investigate how trade policy interacts with inward dfi. Brander and Spencer include unemployment in a model in which the government sets a tariff on imports from the foreign monopolist or output taxes on the foreign monopolist's dfi production. They show that in the presence of unemployment, the home government will choose to set output taxes below tariffs, hence inducing the foreign monopolist to prefer dfi over exporting. Levinsohn investigates tariffs and quotas in oligopolistic industries when the foreign firm(s) can jump the quota by investing directly in the home country. He shows that under certain cost conditions, the presence of inward dfi as quota-jumping is evidence of suboptimal trade policy and that optimal tariffs and quotas are equivalent.

Much international competition, though, now takes place with production in third countries. As a running illustration, we will consider IBM, a U.S. based firm, and the Japan based firm Fujitsu. Each firm produces where they are based and in Singapore. Simultaneous production in two countries by one firm is consistent with rising marginal costs in each location. If marginal 
costs were constant, a cost-minimizing firm would produce its entire output at the cheapest locale. Following Brander and Spencer (1985), we will assume that all production is exported. Finally, we assume that the firms set quantities as their strategic variable. ${ }^{2}$

\subsection{The set-up}

We establish notation at the outset.

$Q_{1}^{1}$ is output by the home firm that takes place in the home country.

$Q_{1}^{3}$ is output by the home firm that takes place in the third country.

$Q_{1}$ is total output by the home firm, so that $Q_{1}=Q_{1}^{1}+Q_{1}^{3}$.

$Q_{2}^{2}$ is output by the foreign firm that takes place in the foreign country.

$Q_{2}^{3}$ is output by the foreign firm that takes place in the third country.

$Q_{2}$ is toyal output by the foreign firm, so that $Q_{2}=Q_{2}^{2}+Q_{2}^{3}$.

To fix ideas, for example, $Q_{1}^{3}$ would be IBM computers produced in Singapore while $Q_{2}^{3}$ are Fujitsu computers produced in Singapore. We will assume that the duopolists produce differentiated products and the price of a product does not depend on where the product is actually produced. An IBM product produced in both the United States and Singapore sells for a single price. Inverse demand functions are denoted by

$$
P^{1}=P^{1}\left(Q_{1}, Q_{2}\right)
$$

and

$$
P^{2}=P^{2}\left(Q_{1}, Q_{2}\right)
$$

Denoting partial derivatives of price with subscripts, we impose the following standard properties on demand:

$$
\begin{aligned}
& P_{1}^{1}, P_{2}^{2}<0 \text { (downward-sloping demand), } \\
& P_{2}^{1}, P_{1}^{2}<0 \text { (substitutes), } \\
& P_{2}^{1}=P_{1}^{2} \text { (symmetry), and } \\
& P_{1}^{1} P_{2}^{2}>P_{2}^{1} P_{1}^{2} \text { (negative semi-definiteness). }
\end{aligned}
$$

For simplicity we will assume that inverse demands are linear.

The total cost of producing $Q_{1}^{1}$ is given by $C_{11}=C_{11}\left(Q_{1}^{1}\right)$ and the marginal cost of producing $Q_{1}^{1}$ is denoted $C_{11}^{\prime} . C_{13}\left(Q_{1}^{3}\right)$ is the total cost of producing

\footnotetext{
${ }^{2}$ It is well understood that firms' mode of market conduct matters when considering optimal policy. See Eaton and Grossman (1986). We will return to this assumption later.
} 
$Q_{1}^{3}$ and the marginal cost of producing $Q_{1}^{3}$ is $C_{13}^{\prime}$. The terms $C_{22}, C_{22}^{\prime}, C_{23}$, and $C_{23}^{\prime}$ are analogously defined. Consistent with the observed phenomenon of simultaneous production at home and abroad by a given firm, we assume increasing marginal costs. For simplicity, we assume these are linear. Hence, $C_{11}^{\prime \prime}, C_{13}^{\prime \prime}, C_{22}^{\prime \prime}$, and $C_{23}^{\prime \prime}>0$ and third derivatives of the total cost function are zero.

A tax (possibly negative, indicating a subsidy) by the home country on output produced at home $\left(Q_{1}^{1}\right)$ is given by $t_{1}$, while a tax on output produced abroad $\left(Q_{1}^{3}\right)$ is given by $t_{3}$. Taxes levied by the third country (Singapore's taxes on IBM and Fujitsu) are given by $t_{\mathrm{f}}$. We will assume the foreign country levies only a tax on output produced at home and this tax is given by $t_{2} \cdot{ }^{3}$

The taxes we consider are levied on output rather than income. Modelling output taxes allows us to more easily draw on the symmetries between trade and tax policies. An alternative approach is to model income taxes, but this would force us to treat some issues that, while interesting (such as the desirability of taxing pure profits), would distract us from our main points. There are, though, certain analogies to income taxation which are worthwhile to make. Setting $t_{3}$ to zero is analogous to the territorial (also called exemption or 'water's edge') system of taxing income, under which foreignsource income is untaxed by the home country. Setting $t_{3}$ to $t_{1}-t_{f}$ is analogous to a worldwide income tax system with unlimited foreign tax credit for taxes paid to foreign governments, under which the total tax paid to all governments is the same for both domestic and foreign-source income. Setting $t_{3}$ to equal $t_{1}$ is analogous to taxing foreign-source income at the same rate as domestic income and treating taxes paid to foreign governments as a cost of business.

\subsection{Optimal policy with endogenous outward $d f i$}

In this subsection we ask what optimal government policy should be when Cournot duopolists who produce off-shore as well as at home compete. The domestic tax and international trade literatures each have considered similar questions. Were it not for potential outward dfi, our set-up would be identical to the simplest Brander-Spencer story in which the home government would find it optimal to subsidize domestic output in order to shift pre-tax profits to the home firm. Were it not for the imperfect competition aspect of our model, our set-up would be the same as those that indicate a

\footnotetext{
${ }^{3}$ Our conclusions are robust to the more complicated story in which the foreign government levies a tax on output abroad also.
} 
government ought to treat taxes paid by domestic firms to foreign governments as simply another business expense. We first derive the optimal policy, then discuss its implications for the choice of policy tools.

The domestic firm's after-tax profits, $\Pi^{1}$, and foreign firm's after-tax profits, $\Pi^{2}$, are given by

$$
\begin{aligned}
& \Pi^{1}=P^{1}\left(Q_{1}, Q_{2}\right)\left(Q_{1}^{1}+Q_{1}^{3}\right)-C_{11}\left(Q_{1}^{1}\right)-C_{13}\left(Q_{1}^{3}\right)-t_{1} Q_{1}^{1}-\left(t_{3}+t_{\mathrm{f}}\right) Q_{1}^{3}, \\
& \Pi^{2}=P^{2}\left(Q_{1}, Q_{2}\right)\left(Q_{2}^{2}+Q_{2}^{3}\right)-C_{22}\left(Q_{2}^{2}\right)-C_{23}\left(Q_{2}^{2}\right)-t_{2} Q_{2}^{2}-t_{\mathrm{f}} Q_{2}^{3} .
\end{aligned}
$$

The first-order conditions assuming an interior solution for the home firm are

$$
\begin{aligned}
& \frac{\partial \Pi^{1}}{\partial Q_{1}^{1}}=0=P^{1}-C_{11}^{\prime}-t_{1}+Q_{1} P_{1}^{1}, \\
& \frac{\partial \Pi^{1}}{\partial Q_{1}^{3}}=0=P^{1}-C_{13}^{\prime}-\left(t_{3}+t_{\mathrm{f}}\right)+Q_{1} P_{1}^{1},
\end{aligned}
$$

while those of the foreign firm are

$$
\begin{aligned}
& \frac{\partial \Pi^{2}}{\partial Q_{2}^{2}}=0=P^{2}-C_{22}^{\prime}-t_{2}+Q_{2} P_{2}^{2}, \\
& \frac{\partial \Pi^{2}}{\partial Q_{2}^{3}}=0=P^{2}-C_{23}^{\prime}-t_{\mathrm{f}}+Q_{2} P_{2}^{2} .
\end{aligned}
$$

Taken pairwise, (3) and (4) like (5) and (6) imply that a firm should, on the margin, be indifferent about where the marginal unit of production occurs. As in Dixit (1984), we differentiate the firms' first-order conditions to establish how firms will respond to policy changes. Taking foreign taxes as fixed $\left(\mathrm{d} t_{2}, \mathrm{~d} t_{\mathrm{f}}=0\right)$, this yields the following system:

$$
\left(\begin{array}{cccc}
2 P_{1}^{1}-C_{11}^{\prime \prime} & 2 P_{1}^{1} & P_{2}^{1} & P_{2}^{1} \\
2 P_{1}^{1} & 2 P_{1}^{1}-C_{13}^{\prime \prime} & P_{2}^{1} & P_{2}^{1} \\
P_{1}^{2} & P_{1}^{2} & 2 P_{2}^{2}-C_{22}^{\prime \prime} & 2 P_{2}^{2} \\
P_{1}^{2} & P_{1}^{2} & 2 P_{2}^{2} & 2 P_{2}^{2}-C_{23}^{\prime \prime}
\end{array}\right)\left(\begin{array}{c}
\mathrm{d} Q_{1}^{1} \\
\mathrm{~d} Q_{1}^{3} \\
\mathrm{~d} Q_{2}^{2} \\
\mathrm{~d} Q_{2}^{3}
\end{array}\right)=\left(\begin{array}{c}
\mathrm{d} t_{1} \\
\mathrm{~d} t_{3} \\
0 \\
0
\end{array}\right) .
$$

This system, albeit simplified by the assumptions of linear marginal costs, linear inverse demands, and Cournot competition, is still difficult to work with when searching for readily interpretable solutions. Here we depart from Dixit's methodology and make use of the fact that the first matrix in (7) has a special form. In particular, the home firm's decisions depend only on the total of the foreign firm's output, but not on where the foreign firm decides 
to produce. Likewise, the foreign firm is not influenced by where the home firm produces.

Let $A=-P_{2}^{1} \mathrm{~d} Q_{2}$ and $B=-P_{1}^{2} \mathrm{~d} Q_{1}$. Then the system in (7) can be decomposed into two subsystems. The subsystem for the home firm is given by

$$
\left(\begin{array}{cc}
2 P_{1}^{1}-C_{11}^{\prime \prime} & 2 P_{1}^{1} \\
2 P_{1}^{1} & 2 P_{1}^{1}-C_{13}^{\prime \prime}
\end{array}\right)\left(\begin{array}{l}
\mathrm{d} Q_{1}^{1} \\
\mathrm{~d} Q_{1}^{3}
\end{array}\right)=\left(\begin{array}{l}
\mathrm{d} t_{1}+A \\
\mathrm{~d} t_{3}+A
\end{array}\right)
$$

The subsystem for the foreign firm is analogously derived:

$$
\left(\begin{array}{cc}
2 P_{2}^{2}-C_{22}^{\prime \prime} & 2 P_{2}^{2} \\
2 P_{2}^{2} & 2 P_{2}^{2}-C_{23}^{\prime \prime}
\end{array}\right)\left(\begin{array}{l}
\mathrm{d} Q_{2}^{2} \\
\mathrm{~d} Q_{2}^{3}
\end{array}\right)=\left(\begin{array}{l}
B \\
B
\end{array}\right)
$$

We will return to the comparative statics results given by these subsystems when analyzing welfare implications of policy choices. For now, though, note that solving (8) for $\mathrm{d} Q_{1}^{1}$ and $\mathrm{d} Q_{1}^{3}$ defines $\mathrm{d} Q_{1}$ and likewise for (9) and $\mathrm{d} Q_{2}$. Doing this allows us to rewrite (7) in a much more manageable form:

$$
\begin{aligned}
& \left(\begin{array}{cc}
2 P_{1}^{1}\left(C_{11}^{\prime \prime}+C_{13}^{\prime \prime}\right)-C_{11}^{\prime \prime} C_{13}^{\prime \prime} & P_{2}^{1}\left(C_{11}^{\prime \prime}+C_{13}^{\prime \prime}\right) \\
P_{1}^{2}\left(C_{22}^{\prime \prime}+C_{23}^{\prime \prime}\right) & 2 P_{2}^{2}\left(C_{22}^{\prime \prime}+C_{23}^{\prime \prime}\right)-C_{22}^{\prime \prime} C_{23}^{\prime \prime}
\end{array}\right)\left(\begin{array}{l}
\mathrm{d} Q_{1} \\
\mathrm{~d} Q_{2}
\end{array}\right) \\
& =\left(\begin{array}{c}
C_{11}^{\prime \prime} \mathrm{d} t_{3}+C_{13}^{\prime \prime} \mathrm{d} t_{1} \\
0
\end{array}\right) .
\end{aligned}
$$

Following Dixit, we will assume that a firm will increase its output ( $Q_{1}$ or $Q_{2}$ ) if it perceives a positive marginal profit from so doing. ${ }^{4}$

The comparative statics that result from (8), (9), and (10) are fairly intuitive. It is straightforward to show, for example, that total output by the home firm will always fall with the imposition of a tax on its output either at home or abroad. That is, $\partial Q_{1} / \partial t_{1}$ and $\partial Q_{1} / \partial t_{3}<0 .^{5}$ Foreign aggregate output, $Q_{2}$, rises with the imposition of domestic taxes, so $\partial Q_{2} / \partial t_{1}$ and $\partial Q_{2} / \partial t_{3}>0$. Finally, the domestic firm adjusts its pattern of production in response to the imposition of domestic taxes. In particular, $\partial Q_{1}^{1} / \partial t_{1}<0$ and $\partial Q_{3}^{1} / \partial t_{3}<0$. The response of domestically produced output to a change in the tax on output produced abroad and the response of dfi output to a change in the domestic tax rate are ambivalent in sign, but knowing that $\partial Q_{1} / \partial t_{1}$

\footnotetext{
${ }^{4}$ The explicit conditions this implies are found in the appendix.

${ }^{5}$ Derivations of these comparative statics results and those that follow are gathered in the appendix.
} 
and $\partial Q_{1} / \partial t_{3}<0$ places bounds on the size of this effect. Suppose, for example, that the home country was contemplating an increase in the tax on output abroad. Then the oligopolistic multinational firm could be expected to respond by decreasing output produced abroad, maybe produce more at home and maybe produce less, but certainly aggregate production by the domestic firm falls.

The home government maximizes welfare, $W$, which, since there is by assumption no domestic consumption, is given by after-tax profits plus home tax revenues, or, equivalently, pre-tax profits less tax payments made to the foreign government:

$$
W=P^{1} Q_{1}-C_{11}-C_{13}-t_{\mathrm{f}} Q_{1}^{3} .
$$

The home government has, in a first-best case, two policy tools, $t_{1}$ and $t_{3}$. It need raise no revenue or, if it must, can levy lump-sum taxes. Taking the taxes set by foreign governments as given, we find that optimal policy is characterized by ${ }^{6}$

$$
t_{1}-t_{3}^{*}=\left(\frac{\partial Q_{1} / \partial t_{3}}{\partial Q_{1}^{3} / \partial t_{3}}\right)\left[t_{1}+Q_{1} P_{2}^{1} \beta\right]
$$

and

$$
t_{1}^{*}-t_{3}=\left(\frac{\partial Q_{1} / \partial t_{1}}{\partial Q_{1}^{3} / \partial t_{1}}\right)\left[t_{1}+Q_{1} P_{2}^{1} \beta\right]
$$

where

$$
\frac{\mathrm{d} Q_{2} / \mathrm{d} t_{3}}{\mathrm{~d} Q_{1} / \mathrm{d} t_{3}}=\frac{\mathrm{d} Q_{2} / \mathrm{d} t_{1}}{\mathrm{~d} Q_{1} / \mathrm{d} t_{1}}=\beta<0
$$

It is straightforward (though tedious) to show that, even when all firms have identical technology $\left(\partial Q_{1} / \partial t_{3}\right) /\left(\partial Q_{1}^{3} / \partial t_{3}\right)$ will not in general equal $\left(\partial Q_{1} / \partial t_{1}\right) /\left(\partial Q_{1}^{3} / \partial t_{1}\right)$. If both equations characterizing optimal policy are to hold,

$$
t_{1}^{*}=t_{3}^{*}=-Q_{1} P_{2}^{1} \beta=Q_{1}\left(\frac{2 P_{2}^{2}\left(C_{22}^{\prime \prime}+C_{23}^{\prime \prime}\right)-C_{22}^{\prime \prime} C_{23}^{\prime \prime}}{\left(C_{22}^{\prime \prime}+C_{23}^{\prime \prime}\right)}\right)<0 .
$$

The optimal policy given by (14) is interesting on several counts. The home government should subsidize equally domestic and dfi output, thus avoiding the inefficiency in the location of production. The optimality of

${ }^{6}$ The reader interested in the derivation of this result is referred to the appendix. 
levying taxes that do not discriminate by location is thus preserved when strategic considerations are introduced.

The optimality of a subsidy instead of a tax directly follows from the assumption of Cournot competition. In this sense, the results are in line with the intuition imparted by the simpler Brander-Spencer profit-shifting models. Had we modelled competition with price as the strategic variable, we conjecture but do not prove that optimal policy would become an export and dfi tax instead of subsidy.

More intuition about optimal policy can be obtained by examining directly the first-order conditions that result from maximizing welfare with respect to the policy instruments. These are given by

$$
t_{1}\left(\frac{\partial Q_{1}^{1}}{\partial t_{3}}\right)+t_{3}^{*}\left(\frac{\partial Q_{1}^{3}}{\partial t_{3}}\right)=-Q_{1} P_{2}^{1}\left(\frac{\partial Q_{2}}{\partial t_{3}}\right)
$$

and

$$
t_{1}^{*}\left(\frac{\partial Q_{1}^{1}}{\partial t_{1}}\right)+t_{3}\left(\frac{\partial Q_{1}^{3}}{\partial t_{1}}\right)=-Q_{1} P_{2}^{1}\left(\frac{\partial Q_{2}}{\partial t_{1}}\right)
$$

In this form, the right-hand side of each equation is the marginal domestic social benefit of increasing a subsidy - the induced increase in the home good's price (multiplied by the domestic firm's total output) resulting from the induced change in the foreign firm's output. The left-hand side is the marginal domestic social cost - the excess burden of inducing output beyond the efficient amount. Because the relationship between the marginal induced price increase to the marginal excess burden is the same for each tax, they are equalized when the two tax rates are identical.

Note that trade policy alone cannot achieve the optimum implied by (14), for trade policy by itself cannot tax or subsidize operations abroad. Because by assumption all domestically produced output is exported, trade policy as typically administrated can monitor and tax or subsidize this output but not dfi output. ${ }^{7}$

Because U.S. domestic tax policy taxes the worldwide income of its multinationals, its tax system is set up to monitor income earned abroad. Thus, while trade policy in this simple model cannot effectively achicve the welfare optimum, tax policy can. The optimal tax policy turns out to be that in which all output, regardless of source, is taxed (subsidized) uniformly and

${ }^{7}$ The optimal trade policy is derived by setting $t_{1}$ while constraining $t_{3}$ to zero. This yields

$$
\left.t_{1}^{*}\right|_{\ell_{3}=0}=-Q_{1} P_{2}^{1}\left(\frac{\mathrm{d} Q_{2} / \mathrm{d} t_{1}}{\mathrm{~d} Q_{1}^{1} / \mathrm{d} t_{1}}\right)
$$

which is identical to (14) except that in the denominator $\partial Q_{1}^{1} / \partial t_{1}$ replaces $\partial Q_{1} / \partial t_{1}$. 
taxes paid to foreign governments are simply treated as another business expense. One interpretation of (14) is that optimal policy targets the strategic 'distortion' without interfering with productive efficiency. ${ }^{8}$

The above results suggest that trade policy alone is inferior to domestic tax policy alone in the presence of multinational firms. (Without dfi, the optimal domestic tax policy and trade policy are equivalent.) However, this result follows necessarily only in our very simple partial equilibrium framework. In any real economy, though, there are sure to be many industries and not all will be Cournot duopolists facing identical inverse demand curves i.e. not all should be largeted for a subsidy. National tax policy, though, is not set on an industry level. ${ }^{9}$ Although domestic tax policy can tax the

${ }^{8}$ That optimal taxes on firms are zero in the absence of a strategic motive $\left(P_{2}^{1}=0\right)$ and negative in its presence may be surprising to students of taxation who are accustomed to positive taxes. These results, of course, depend on the absence of a revenue requirement (and the Cournot assumption). Introducing a revenue requirement could generate positive taxes, but to solve this problem would require a full-blown optimal taxation treatment. We do know, though, that if pure profits can be taxed and if a full set of commodity taxes is available, the optimal tax structure in the absence of international strategic considerations will feature production efficiency, which in this case implies that $t_{1}=t_{3}$.

Requiring that the two taxes themselves raise a fixed amount of revenue (for, perhaps, political reasons) does change the results. To demonstrate this, maximize (11) subject to the constraint that $t_{1} Q_{1}^{1}+t_{3} Q_{1}^{3}$ be a constant, and let $\tau$ be the Lagrange multiplier on this constraint. Then it can be shown that

$$
t_{1}^{*}=\frac{1}{1-\tau}\left(-Q_{1} P_{2}^{1} \beta+\tau\left[\frac{\frac{Q_{1}^{1} \mathrm{~d} Q_{1}^{3}}{\mathrm{~d} t_{3}}-\frac{Q_{1}^{3} \mathrm{~d} Q_{1}^{3}}{\mathrm{~d} t_{1}}}{\Delta}\right]\right)
$$

and

$$
t_{3}^{*}=\frac{1}{1-\tau}\left(-Q_{1} P_{2}^{1} \beta+\tau\left[\frac{\frac{Q_{1}^{3} \mathrm{~d} Q_{1}^{1}}{\mathrm{~d} t_{1}}-\frac{Q_{1}^{1} \mathrm{~d} Q_{1}^{1}}{\mathrm{~d} t_{3}}}{\Delta}\right]\right),
$$

where

$$
\Delta=\frac{\partial Q_{1}^{3}}{\partial t_{1}} \frac{\partial Q_{1}^{1}}{\partial t_{3}}-\frac{\partial Q_{1}^{1}}{\partial t_{1}} \frac{\partial Q_{1}^{3}}{\partial t_{3}}
$$

Clearly when $\tau=0$, we are back to our earlier results. When $\tau$ is not zero, $t_{1}^{*}$ will equal $t_{3}^{*}$ only when

$$
\left(\frac{\partial Q_{1} / \partial t_{1}}{Q_{1}^{1}}\right)=\left(\frac{\partial Q_{1} / \partial t_{3}}{Q_{1}^{3}}\right)
$$

Unless this condition holds, the revenue raised per excess burden will not be equal when the two taxes are equal, and it will be optimal to tax at a higher rate the location for which output is relatively high compared with its responsiveness to taxation.

${ }^{9}$ This is a slight exaggeration. Tax reform bills inevitably contain certain firm-specific provisions (known as 'transition rules') designed to shield fortunate firms from the negative consequences of the new tax law. Moreover, tax laws can be indirectly industry-specific. For example, the investment tax credit provided more benefit to equipment and machinery intensive industries such as automobile manufacturing than it did to other industries such as retailing and pharmaceuticals. Nevertheless, we believe as a generalization that trade policy is more industryspecific than tax policy. The legislative processes by which trade and tax policy are enacted reinforce this view. Tax policy is typically a congressional matter so that both houses of 
worldwide income of firms (and this is an advantage), it cannot typically set rates on an industry basis (and this is a disadvantage). In the following section, we extend our model to include a second industry that is perfectly competitive. We then re-examine some of the above results.

\section{The multi-industry economy}

We introduce into the partial equilibrium model a second domestic industry. This industry's output must be taxed on the same terms as that of the first industry. The key difference between the first and second industries is that the second industry is assumed to treat the international price of its output as exogenous. This captures the idea that the firm in each country is small in the world market for its output. As in the imperfectly competitive industry, the firms in the competitive industry are assumed to engage in outward direct foreign investment. We refer to this second industry as the non-strategic industry.

Notation for the non-strategic industry is the same as for the strategic industry except lower-case letters are used instead of capital letters. Hence $q_{1}$ is the total output by the home firm of which $q_{11}$ is produced domestically and $q_{13}$ is produced abroad. This output sells for the exogenous price $p^{1}$.

\subsection{Domestic tax policy}

We now investigate domestic optimal tax policy assuming that the tax rates on both domestic and foreign corporate output cannot be industryspecific. For now, trade policy is assumed unavailable. This captures the idea that while the GATT restricts a nation's ability to set trade taxes and subsidies, tax policy (including the tax treatment of foreign-source income) is beyond GATT's reach. Is it still the case that the tax or subsidy rates on domestic and foreign output are, at the welfare optimum, identical?

Profits for the home firm in the non-strategic industry are given by

$$
\pi_{1}=p^{1}\left(q_{1}^{1}+q_{1}^{3}\right)-c_{11}\left(q_{1}^{1}\right)-c_{13}\left(q_{1}^{3}\right)-t_{1} q_{1}^{1}-\left(t_{3}+t_{\mathrm{f}}\right) q_{1}^{3} .
$$

Foreign firm profits are

$$
\pi_{2}=p^{2}\left(q_{2}^{2}+q_{2}^{3}\right)-c_{22}\left(q_{2}^{2}\right)-c_{23}\left(q_{2}^{3}\right)-t_{2} q_{2}^{2}-t_{\mathrm{f}} q_{2}^{3} .
$$

Profit maximization by the home firm implies that $p^{1}=c_{11}^{\prime}+t_{1}=c_{13}^{\prime}+t_{3}+t_{\mathrm{f}}$ while for the foreign firm $p^{2}=c_{22}^{\prime}+t_{2}=c_{23}+t_{\mathrm{f}}$. Differentiating each firm's

Congress must approve such measures. This plausibly leads to broader policy than trade policy. Much trade policy is set in response to particular trade disputes brought before the ITC, and these suits are frequently very industry-specific. 
first-order conditions, we show how firms respond to changes in the policy environment (taking foreign taxes, $t_{\mathrm{f}}$ and $t_{2}$, as fixed). This system is given by

$$
\left(\begin{array}{cc}
-c_{11}^{\prime \prime} c_{13}^{\prime \prime} & 0 \\
0 & -c_{22}^{\prime \prime} c_{23}^{\prime \prime}
\end{array}\right)\left(\begin{array}{l}
\mathrm{d} q_{1} \\
\mathrm{~d} q_{2}
\end{array}\right)=\left(\begin{array}{c}
c_{13}^{\prime \prime} \mathrm{d} t_{1}+c_{11}^{\prime \prime} \mathrm{d} t_{3} \\
0
\end{array}\right)
$$

Home firm output, $q_{1}$, falls with a rise in either of the taxes on its output. Foreign firm output, $q_{2}$, is unaffected by the home country's tax policies since as the home firm cuts back output in response to a tax, the world prices in the non-strategic industry are unchanged.

Home country welfare is now

$$
W=P^{1} Q_{1}-C_{11}-C_{13}+p^{1} q_{1}-c_{11}-c_{13}-t_{\mathbf{f}}\left(Q_{1}^{3}+q_{1}^{3}\right)
$$

Differentiating this expression with respect to $t_{1}$ and $t_{3}$, respectively, and employing substitutions analogous to those used to derive (12) yields

$$
t_{1}^{*}-t_{3}=\left(\frac{\partial Q_{1}^{3}}{\partial t_{1}}+\frac{\partial q_{1}^{3}}{\partial t_{1}}\right)^{-1}\left(t_{1}+Q_{1} P_{2}^{1} \beta\right) \frac{\partial Q_{1}}{\partial t_{1}}+t_{1} \frac{\partial q_{1}}{\partial t_{1}}
$$

and

$$
t_{1}-t_{1}^{*}=\left(\frac{\partial Q_{1}^{3}}{\partial t_{3}}+\frac{\partial q_{1}^{3}}{\partial t_{3}}\right)^{-1}\left(t_{1}+Q_{1} P_{2}^{1} \beta\right) \frac{\partial Q_{1}}{\partial t_{3}}+t_{1} \frac{\partial q_{1}}{\partial t_{3}}
$$

Unlike the single industry case in section 2 , it is no longer true that the first-best solution entails taxing (or subsidizing) domestic output and dfi output at equal rates. Foreign production may now deserve special consideration.

Solving (19) and (20) for the optimal $t_{1}$ and $t_{3}$ yields closed-form solutions for the optimal policy. The interested reader is referred to the appendix. The magnitudes of optimal policies are not especially informative. It remains the case, though, that optimal policy is still a subsidy on domestic and foreign output, albeit at perhaps differing rates. Also, in the absence of the nonstrategic industry, the formula for optimal policy reduces to the optimal policy given in (14).

More appealing economic intuition about how the home government ought to set $t_{1}$ and $t_{3}$ is obtained by examining the relative magnitudes of these policy instruments. It is straightforward to show (and derived in the appendix) that

$$
\left|t_{1}^{*}\right| \gtreqless\left|t_{3}^{*}\right|, \quad \text { iff } \frac{C_{13}^{\prime \prime}}{C_{11}^{\prime \prime}} \gtreqless \frac{c_{13}^{\prime \prime}}{c_{11}^{\prime \prime}} .
$$


To interpret (21) with an illustrative example, suppose the strategic firm is still IBM and the non-strategic firm is Weyerhauser (W). Assume W produces at home as well as in Malaysia. Then if IBM's dfi technology and its domestic technology are the same (up to an intercept of the MC curve) and similarly for $\mathrm{W}$, then the optimal subsidies on domestic and dfi output are identical, and the optimal policy has the same form as in the oneindustry case.

Now suppose instead that all else is the same except the marginal cost curve for W's dfi output is steeper than it is at home, and therefore foreign output is less responsive to changes in output price or cost. This might result if $\mathrm{W}$ has a smaller labor pool to draw upon at their foreign plant than at their domestic plant. Eq. (21) tells us that, since $c_{13}^{\prime \prime}>c_{11}^{\prime \prime},\left|t_{3}^{*}\right|>\left|t_{1}^{*}\right|$. That is, the subsidy is greater on W's dfi output. If the marginal cost of W's domestic production were steeper than that of its dfi production, all else equal, the subsidy would be greater on domestic output. This is because in the nonstrategic sector, subsidies cause excess burden with no offsetting strategic advantage. Hence, the optimal policy will tend to avoid subsidizing production in the locale where aggregate output of the non-strategic sector is most responsive. That is, it will tend to avoid subsidizing the locale where the nonstrategic sector has a flatter marginal cost curve because the marginal excess burden is greater there. Alternatively, it will tend to subsidize the locale where the strategic sector has a flatter marginal cost curve. For a given amount of excess burden, the strategic benefit of a subsidy is greater when it induces a greater domestic output response. Thus, foreign production should be subsidized at a higher rate than domestic production if, on the margin, more of the output of the strategic sector is produced abroad relative to the nonstrategic sector.

\subsection{Tax and trade policy}

We have shown that considering the presence of a non-strategic industry, which must be taxed identically to the strategic sector, renders the uniform treatment of domestic and dfi output non-optimal. Underlying this result is the inability of domestic tax policy to target specific industries. Note, though, that in spite of GATT regulations, nations often have access to both tax and trade policy. Even with tax and trade policy available, the government is still constrained in its policy instruments. While trade policy allows the net tax or subsidy on domestic production to be industry-specific, the tax or subsidy on production abroad, $t_{3}$, remains constant across industries. In what follows we investigate optimal tax and trade policy when trade, but not tax, policy can be industry-specific.

The non-strategic industry faces an effective tax rate of $t_{1}$ on its domestic production, while the effective tax rate on the strategic industry's output is 
now denoted $T_{1}$. Output produced abroad is still taxed or subsidized at rate $t_{3}$ regardless of industry.

The home government sets $t_{3}, t_{1}$, and $T_{1}$ independently yielding the following first-order conditions:

$$
\begin{aligned}
& T_{1} \frac{\partial Q_{1}^{1}}{\partial t_{3}}+t_{1} \frac{\partial q_{1}^{1}}{\partial t_{3}}+t_{3}\left(\frac{\partial Q_{1}^{3}}{\partial t_{3}}+\frac{\partial q_{1}^{3}}{\partial t_{3}}\right)=-Q_{1} P_{2}^{1} \beta \frac{\partial Q_{1}}{\partial t_{3}} \\
& t_{1} \frac{\partial q_{1}^{1}}{\partial t_{1}}+t_{3} \frac{\partial q_{1}^{3}}{\partial t_{1}}=0 \\
& T_{1} \frac{\partial Q_{1}^{1}}{\partial T_{1}}+t_{3} \frac{\partial Q_{1}^{3}}{\partial T_{1}}=-Q_{1} P_{2}^{2} \beta \frac{\partial Q_{1}}{\partial T_{1}}
\end{aligned}
$$

Differentiating the first-order conditions for the non-strategic firm gives

$$
\left(\begin{array}{cc}
-c_{11}^{\prime \prime} & 0 \\
0 & -c_{13}^{\prime \prime}
\end{array}\right)\left(\begin{array}{l}
\mathrm{d} q_{1}^{1} \\
\mathrm{~d} q_{1}^{3}
\end{array}\right)=\left(\begin{array}{l}
\mathrm{d} t_{1} \\
\mathrm{~d} t_{3}
\end{array}\right),
$$

and this implies that $\partial q_{1}^{3} / \partial t_{1}=0$. Substituting this result into (23) yields

$$
t_{1} \frac{\partial q_{1}^{1}}{\partial t_{1}}=0
$$

Since (25) implies that $\partial q_{1}^{1} / \partial t_{1} \neq 0$, the optimal tax on domestic production in the non-strategic industry, $t_{1}^{*}$, is zero. Furthermore, $\left(23^{\prime}\right)$ places no restrictions on $t_{3}$, so henceforth only (22) and (24) are considered. Imposing $t_{1}^{*}=0$, and solving for $T_{1}^{*}$ and $t_{3}^{*}$, we find

$$
\begin{aligned}
& T^{*}=\frac{\left(-Q_{1} P_{2}^{1} \beta \frac{\partial Q_{1}}{\partial t_{3}}\right) \frac{\partial Q_{1}^{3}}{\partial T_{1}}+\left(\frac{\partial Q_{1}^{3}}{\partial t_{3}}+\frac{\partial q_{1}^{3}}{\partial t_{3}}\right)\left(Q_{1} P_{2}^{1} \beta \frac{\partial Q_{1}}{\partial T_{1}}\right)}{D}, \\
& t_{3}^{*}=\underbrace{\left(-Q_{1} P_{2}^{1} \beta \frac{\partial Q_{1}}{\partial T_{1}}\right) \frac{\partial Q_{1}^{1}}{\partial t_{3}}+\frac{\partial Q_{1}^{1}}{\partial T_{1}}\left(Q_{1} P_{2}^{1} \beta \frac{\partial Q_{1}}{\partial t_{3}}\right)} \underbrace{}_{D}
\end{aligned}
$$

where

$$
D=\frac{\partial Q_{1}^{1}}{\partial t_{3}} \frac{\partial Q_{1}^{3}}{\partial T_{1}}-\left(\frac{\partial Q_{1}^{3}}{\partial t_{3}}+\frac{\partial q_{1}^{3}}{\partial t_{3}}\right) \frac{\partial Q_{1}^{1}}{\partial T_{1}}<0
$$

It is straightforward to show that $T_{1}^{*}$ and $t_{3}^{*}$ remain subsidies (i.e. they are 
negative). A much more striking result is obtained by subtracting $t_{3}$ from $T_{1}$ as shown below:

$$
\begin{aligned}
\left(T_{1}^{*}-t_{3}^{*}\right) D= & -Q_{1} P_{2}^{1} \beta \frac{\partial Q_{1}}{\partial t_{3}} \frac{\partial Q_{1}^{3}}{\partial T_{1}}+Q_{1} P_{2}^{1} \beta \frac{\partial Q_{1}}{\partial T_{1}} \frac{\partial Q_{1}^{3}}{\partial t_{3}} \\
& +Q_{1} P_{2}^{1} \beta \frac{\partial Q_{1}}{\partial T_{1}} \frac{\partial Q_{1}^{1}}{\partial t_{3}}-Q_{1} P_{2}^{1} \beta \frac{\partial Q_{1}}{\partial t_{3}} \frac{\partial Q_{1}^{1}}{\partial T_{1}}+Q_{1} P_{2}^{1} \beta \frac{\partial q_{1}^{3}}{\partial t_{3}} \\
= & Q_{1} P_{2}^{1} \beta\left[-\frac{\partial Q_{1}}{\partial t_{3}}\left(\frac{\partial Q_{1}^{3}}{\partial T_{1}}+\frac{\partial Q_{1}^{1}}{\partial T_{1}}\right)+\frac{\partial Q_{1}}{\partial T_{1}}\left(\frac{\partial Q_{1}^{3}}{\partial t_{3}}+\frac{\partial Q_{1}^{1}}{\partial t_{3}}\right)\right] \\
& +Q_{1} P_{2}^{1} \beta \frac{\partial q_{1}^{3}}{\partial t_{3}}
\end{aligned}
$$

The entire term in square brackets equals zero and we are left with

$$
\left(T_{1}^{*}-t_{3}^{*}\right)=\frac{Q_{1} P_{2}^{1} \beta \frac{\partial q_{1}^{3}}{\partial t_{3}}}{D} \leqq 0 .
$$

Since $T_{1}^{*}$ and $t_{3}^{*}$ are always negative, (28) implies that the optimal subsidy on domestic output by the strategic firm is always greater than or equal to the optimal subsidy on dfi output. The intuition behind this finding as as follows. Since tax policy cannot discriminate between industries, any subsidy to output abroad in the strategic industry entails an equal subsidy to output abroad by the non-strategic industry. This subsidy to the non-strategic industry produces a deadweight loss which must be weighed against the profit-shifting that the subsidy induces in the strategic industry. $T_{1}^{*}$, on the other hand, is specific to the strategic industry and does not produce any deadweight loss in the non-strategic industry. Hence the subsidy on dfi output is smaller (in absolute value) than the subsidy to domestic output in the strategic industry. The inability to target industry-specific tax treatment of foreign-source income results in production inefficiency.

In practice, the pattern of $T_{1}<t_{3}<t_{1}$ can be achieved in an income tax system in a number of different ways. One scheme would provide preferential treatment to domestic-source income, but then levy an export ${ }^{10} \operatorname{tax}$ targeted to the non-strategic sector that is sufficiently high that its domestic output is taxed relative to both the domestic output of the strategic sector and all dfi

\footnotetext{
${ }^{10}$ Recall the assumption of the model that all output is exported and sold in a third country, so an export tax is equivalent to a domestic output tax.
} 
output. Alternatively, foreign-source income could receive preferential tax treatment compared with domestic income, while domestic output of the strategic sector receives an export subsidy that is generous enough to make it, all in all, tax preferred to both foreign output and domestic output of the non-strategic sector. This latter scenario bears a more than passing resemblance to tax and trade policy as they are actually practiced in several developed countries.

\section{Conclusions}

Suppose that there are certain industries for which subsidization can successfully cause a shift of pre-tax profits from foreign to domestic firms, and certain industries for which this would be ineffective. In this case, in the context of our simple model, the optimal industry-specific policy is straightforward - subsidize the former set of industries (which we call 'strategic') and do not subsidize the latter ('non-strategic') ones. Furthermore, set the subsidies so that there is no fiscal incentive to locate production either domestically or abroad.

In the absence of industry-specific policies, the usual policy prescription that policy should not introduce locational distortions should be abandoned. If policy must be completely industry-blind, then policy should favor production located where output of the strategic sector is relatively more responsive, in order to maximize the strategic gains net of the excess burden created. If tariff (but not tax) policy can be made industry-specific, net subsidies should favor domestic production of the strategic industry, ignore domestic production of the non-strategic industry, and subsidize foreign output at a lower rate than domestic output of the strategic sector. The ability to effectively target the subsidy on domestic output makes it a more effective instrument than the subsidy on foreign output, which cannot be targeted to strategic sectors.

The optimal policy described here could be implemented by having a preferential tax rate on foreign income combined with an export subsidy targeted to the strategic sector. Note, though, that in no case does the optimal tax on foreign-source income depend on the rate imposed by the host country, thus ruling out widespread schemes such as the limited foreign tax credit under which $t_{3}=\max \left(t_{1}-t_{\mathrm{f}}, 0\right)$. Credit-type tax systems, though, frequently emerge as an optimal outcome when investigating multilateral tax policy under perfect competition. While we show that credit-type schemes do not emerge as optimal unilateral policy under imperfect competition, extending our analysis to multilateral concerns is a potentially rich direction for future research. For example, how should post-1992 Europe structure tax and trade policy if its objective is aggregate European welfare? 
The concluding comments to almost any paper investigating strategic trade and/or tax policy would be remiss were they not to remind the reader of the general lack of robustness that accompanies the literature. In particular, results frequently depend on the choice of strategy space, whether or not markets are segmented or integrated, whether or not domestic firms sell their product at home, and whether or not there is free entry. As such, one should be extremely careful in drawing any policy conclusions from stylized models such as those presented in this paper. Nevertheless, exercises of this type can be valuable in framing the policy debate by clarifying the cconomic conditions which must exist in order for policy intervention to be potentially advantageous. We hope this paper works toward convincing researchers of the need to integrate public economics, international trade, and industrial organization when considering policy affecting today's global corporation.

\section{Appendix}

A.1. Stability results and comparative statics results used in section 2

A sufficient condition for the stability of (10) is that

$$
\begin{aligned}
& {\left[2 P_{1}^{1}\left(C_{11}^{\prime \prime}+C_{13}^{\prime \prime}\right)-C_{11}^{\prime \prime} C_{13}^{\prime \prime}\right]\left[2 P_{2}^{2}\left(C_{22}^{\prime \prime}+C_{23}^{\prime \prime}\right)-C_{22}^{\prime \prime} C_{23}^{\prime \prime}\right]} \\
& -\left[P_{2}^{1}\left(C_{11}^{\prime \prime}+C_{13}^{\prime \prime}\right)\right]\left[P_{1}^{2}\left(C_{22}^{\prime \prime}+C_{23}^{\prime \prime}\right)\right]>0, \\
& 2 P_{1}^{1}\left(C_{11}^{\prime \prime}+C_{13}^{\prime \prime}\right)-C_{11}^{\prime \prime} C_{13}^{\prime \prime}<0, \\
& 2 P_{2}^{2}\left(C_{22}^{\prime \prime}+C_{23}^{\prime \prime}\right)-C_{22}^{\prime \prime} C_{23}^{\prime \prime}<0 .
\end{aligned}
$$

This condition is useful in signing the following comparative statics results:

$$
\frac{\partial Q_{1}}{\partial t_{1}}=\frac{C_{13}^{\prime \prime}\left(2 P_{2}^{2}\left(C_{22}^{\prime \prime}+C_{23}^{\prime \prime}\right)-C_{22}^{\prime \prime} C_{23}^{\prime \prime}\right)}{|D|}<0
$$

where

$$
|D|=\left[2 P_{1}^{1}\left(C_{11}^{\prime \prime}+C_{13}^{\prime \prime}\right)-C_{11}^{\prime \prime} C_{13}^{\prime \prime}\right]\left[2 P_{2}^{2}\left(C_{22}^{\prime \prime}+C_{23}^{\prime \prime}\right)-C_{22}^{\prime \prime} C_{23}^{\prime \prime}\right]-
$$
$\left[P_{2}^{1}\left(C_{11}^{\prime \prime}+C_{13}^{\prime \prime}\right)\right]\left[P_{1}^{2}\left(C_{22}^{\prime \prime}+C_{23}^{\prime \prime}\right)\right]$ which is positive by the stability conditions of (A.1).

$$
\begin{aligned}
& \frac{\partial Q_{1}}{\partial t_{3}}=\frac{C_{11}^{\prime \prime}\left(2 P_{2}^{2}\left(C_{22}^{\prime \prime}+C_{23}^{\prime \prime}\right)-C_{22}^{\prime \prime} C_{23}^{\prime \prime}\right)}{|D|}<0, \\
& \frac{\partial Q_{2}}{\partial t_{1}}=\frac{-C_{13}^{\prime \prime} P_{1}^{2}\left(C_{22}^{\prime \prime}+C_{23}^{\prime \prime}\right)}{|D|}>0,
\end{aligned}
$$




$$
\frac{\partial Q_{2}}{\partial t_{3}}=\frac{-C_{11}^{\prime \prime} P_{1}^{2}\left(C_{22}^{\prime \prime}+C_{23}^{\prime \prime}\right)}{|D|}>0 .
$$

Using (8), we derive the following three results:

$$
\begin{aligned}
\frac{\partial Q_{1}^{1}}{\partial t_{1}} & =\frac{\left(1-P_{2}^{1} \frac{\partial Q_{2}}{\partial t_{1}}\right)\left(2 P_{1}^{1}-C_{13}^{\prime \prime}\right)+\left(2 P_{1}^{1} P_{2}^{1} \frac{\partial Q_{2}}{\partial t_{1}}\right)}{|E|} \\
& =\frac{2 P_{1}^{1}-C_{13}^{\prime \prime}+P_{2}^{1} C_{13}^{\prime \prime} \frac{\partial Q_{2}}{\partial t_{1}}}{|E|}<0,
\end{aligned}
$$

where

$$
|E|=\left(2 P_{1}^{1}-C_{11}^{\prime \prime}\right)\left(2 P_{1}^{1}-C_{13}^{\prime \prime}\right)-\left(2 P_{1}^{1}\right)\left(2 P_{1}^{1}\right)=C_{11}^{\prime \prime} C_{13}^{\prime \prime}-2 P_{1}^{1} C_{11}^{\prime \prime}-
$$
$2 P_{1}^{1} C_{13}^{\prime \prime}>0$. Similarly,

$$
\begin{aligned}
& \frac{\partial Q_{1}^{3}}{\partial t_{3}}=\frac{2 P_{1}^{1}-C_{11}^{\prime \prime}+P_{2}^{1} C_{11}^{\prime \prime} \frac{\partial Q_{2}}{\partial t_{3}}}{|E|}<0 \\
& \frac{\partial Q_{1}^{3}}{\partial t_{1}}=\frac{C_{11}^{\prime \prime} P_{2}^{1} \frac{\partial Q_{2}}{\partial t_{1}}-2 P_{1}^{1}}{|E|}
\end{aligned}
$$

and $\partial Q_{1}^{3} / \partial t_{1}$ is ambiguously signed.

\section{A.2. Derivation of (12) and (13)}

Maximizing welfare with respect to $t_{3}$ yields

$$
\begin{aligned}
\frac{\partial W}{\partial t_{3}}=0 & =P^{1} \frac{\partial Q_{1}}{\partial t_{3}}+Q_{1}\left(P_{1}^{1} \frac{\partial Q_{1}}{\partial t_{3}}+P_{2}^{1} \frac{\partial Q_{2}}{\partial t_{3}}\right)-C_{11}^{\prime} \frac{\partial Q_{1}^{1}}{\partial t_{3}}-\left(C_{13}^{\prime}+t_{\mathrm{f}}\right) \frac{\partial Q_{1}^{3}}{\partial t_{3}} \\
& =P^{1} \frac{\partial Q_{1}}{\partial t_{3}}+Q_{1}\left(P_{1}^{1} \frac{\partial Q_{1}}{\partial t_{3}}+P_{2}^{1} \frac{\partial Q_{2}}{\partial t_{3}}\right)-C_{11}^{\prime} \frac{\partial Q_{1}^{1}}{\partial t_{3}} \\
& -\left(C_{11}^{\prime}+t_{1}-t_{3}\right) \frac{\partial Q_{1}^{3}}{\partial t_{3}} \\
& =P^{1} \frac{\partial Q_{1}}{\partial t_{3}}+Q_{1}\left(P_{1}^{1} \frac{\partial Q_{1}}{\partial t_{3}}+P_{2}^{1} \frac{\partial Q_{2}}{\partial t_{3}}\right)-C_{11}^{\prime} \frac{\partial Q_{1}}{\partial t_{3}}-\left(t_{1}-t_{3}\right) \frac{\partial Q_{1}^{3}}{\partial t_{3}}
\end{aligned}
$$


Rearranging, we have

$$
t_{1}-t_{3}^{*}=\left(\frac{\partial Q_{1}^{3}}{\partial t_{3}}\right)^{-1}\left(\left(P^{1}+P_{1}^{1} Q_{1}-C_{11}^{\prime}\right) \frac{\partial Q_{1}}{\partial t_{3}}+Q_{1} P_{2}^{1} \frac{\partial Q_{2}}{\partial t_{3}}\right)
$$

where $t_{3}^{*}$ denotes the optimal tax on output produced abroad.

The home government simultaneously sets the optimal tax on domestic production. Manipulations similar to those used to arrive at (A.9) yield the following expression for $t_{1}^{*}$ :

$$
t_{1}^{*}-t_{3}=\left(\frac{\partial Q_{1}^{3}}{\partial t_{1}}\right)^{-1}\left(\left(P^{1}+P_{1}^{1} Q_{1}-C_{11}^{\prime}\right) \frac{\partial Q_{1}}{\partial t_{1}}+Q_{1} P_{2}^{1} \frac{\partial Q_{2}}{\partial t_{1}}\right)
$$

Taken as a system, (A.9) and (A.10) implicitly define the optimal taxes on domestically produced (and exported) output and output produced abroad. Some manipulation is required to obtain closed-form solutions.

First note that by applying Cramer's rule to (10), it is straightforward to prove that

$$
\frac{\partial Q_{1}}{\partial t_{1}} \frac{C_{11}^{\prime \prime}}{C_{13}^{\prime \prime}}=\frac{\partial Q_{1}}{\partial t_{3}} \text { and } \quad \frac{\partial Q_{2}}{\partial t_{1}} \frac{C_{11}^{\prime \prime}}{C_{13}^{\prime \prime}}=\frac{\partial Q_{2}}{\partial t_{3}}
$$

This implies that $Q_{1}$ and $Q_{2}$ adjust in a constant proportion to changes in either $t_{1}$ or $t_{3}$. It is useful to define the ratio of these changes as

$$
\frac{\mathrm{d} Q_{2} / \mathrm{d} t_{3}}{\mathrm{~d} Q_{1} / \mathrm{d} t_{3}}=\frac{\mathrm{d} Q_{2} / \mathrm{d} t_{1}}{\mathrm{~d} Q_{1} / \mathrm{d} t_{1}}=\beta<0
$$

Making use of this term, and noting that (3) implies $P^{1}+Q_{1} P_{1}^{1}-C_{11}^{\prime \prime}=t_{1}$, we obtain (12) and (13).

A.3. Additional comparative statics results used in section 3 and derivation of (21)

The following comparative statics results prove useful:

$$
\begin{aligned}
& \frac{\partial q_{1}}{\partial t_{1}}=\frac{\partial q_{1}^{1}}{\partial t_{1}}=\frac{-1}{c_{11}^{\prime \prime}}<0 \\
& \frac{\partial q_{1}}{\partial t_{3}}=\frac{\partial q_{1}^{3}}{\partial t_{3}}=\frac{-1}{c_{13}^{\prime \prime}}<0 .
\end{aligned}
$$

Solving (19) and (20) for the optimal $t_{1}$ and $t_{3}$ yields 


$$
t_{1}^{*}=\frac{\left(\frac{\partial Q_{1}^{3}}{\partial t_{1}}+\frac{\partial q_{1}^{3}}{\mathrm{~d} t_{1}}\right)\left(Q_{1} P_{2}^{1} \beta \frac{\partial Q_{1}}{\partial t_{3}}\right)-\left(\frac{\partial Q_{1}^{3}}{\partial t_{3}}+\frac{\partial q_{1}^{3}}{\mathrm{~d} t_{3}}\right)\left(Q_{1} P_{2}^{1} \beta \frac{\partial Q_{1}}{\partial t_{1}}\right)}{\left(\frac{\partial Q_{1}}{\partial t_{1}}+\frac{\partial q_{1}}{\mathrm{~d} t_{1}}\right)\left(\frac{\partial Q_{1}^{3}}{\partial t_{3}}+\frac{\partial q_{1}^{3}}{\mathrm{~d} t_{3}}\right)-\left(\frac{\partial Q_{1}^{3}}{\partial t_{1}}+\frac{\partial q_{1}^{3}}{\mathrm{~d} t_{1}}\right)\left(\frac{\partial Q_{1}}{\partial t_{3}}+\frac{\partial q_{1}}{\mathrm{~d} t_{3}}\right)}
$$

and

$$
t_{3}^{*}=\frac{\left(\frac{\partial Q_{1}^{1}}{\partial t_{3}}+\frac{\partial q_{1}^{1}}{\partial t_{3}}\right) Q_{1} P_{2}^{1} \beta \frac{\partial Q_{1}}{\partial t_{1}}-\left(\frac{\partial Q_{1}^{1}}{\partial t_{1}}+\frac{\partial q_{1}^{1}}{\partial t_{1}}\right) Q_{1} P_{2}^{1} \beta \frac{\partial Q_{1}}{\partial t_{3}}}{\left(\frac{\partial Q_{1}}{\partial t_{1}}+\frac{\partial q_{1}}{\mathrm{~d} t_{1}}\right)\left(\frac{\partial Q_{1}^{3}}{\partial t_{3}}+\frac{\partial q_{1}^{3}}{\mathrm{~d} t_{3}}\right)-\left(\frac{\partial Q_{1}^{3}}{\partial t_{1}}+\frac{\partial q_{1}^{3}}{\mathrm{~d} t_{1}}\right)\left(\frac{\partial Q_{1}}{\partial t_{3}}+\frac{\partial q_{1}}{\mathrm{~d} t_{3}}\right)}
$$

Substituting the immediately above comparative statics results for how firms adjust outputs in response to policy changes into (A.14) (and (A.15) and rearranging gives $(21)$ in the main text.

\section{References}

Arthur Young and Company, 1988, The competitive burden: Tax treatment of U.S. multinationals. A Tax Foundation Special Report (Washington, DC).

Brander, J. and B. Spencer, 1985, Export subsidies and intnational market share rivalry, Journal of International Economics 18, 83-100.

Brander, J. and B. Spencer, 1987, Foreign direct investment with unemployment and endogenous taxes and tariffs, Journal of International Economics 22, 257-279.

Dixit, A., 1984, International trade policy for oligopolistic industries, Economic Journal 94, 305-312.

Dixit, A., 1985, Tax policy for open economics, in: A. Auerbach and M. Feldstein, eds., The handbook of public economics, Vol. 1 (North-Holland, Amsterdam).

Eaton, J. and G. Grossman, 1986, Optimal trade and industrial policy under oligopoly, Quarterly Journal of Economics 101, 383-406.

Ethier, W. and H. Horn, 1990, Managerial control of international firms and patterns of direct investment, Journal of International Economics 28, 25-46.

Gordon, R. and J. Levinsohn, 1990, The linkage between domestic taxes and border taxes, in: A. Razin and J. Slemrod, eds., Taxation in the global economy (University of Chicago Press, Chicago, IL).

Levinsohn, J., 1989, Strategic trade policy when firms can invest abroad: When are tariffs and quotas equivalent?, Journal of International Economics 27, 129-146.

Slemrod, J., 1991, Competitive advantage and the optimal tax treatment of the foreign-source income of multinationals: The case of the U.S. and Japan, American Journal of Tax Policy 9 , 113-143. 